\title{
The relationship between chronic pain and health-related quality of life in long-term social assistance recipients in Norway
}

\author{
Borghild Løyland • Christine Miaskowski • \\ Steven M. Paul • Espen Dahl • Tone Rustøen
}

Accepted: 28 June 2010/Published online: 22 July 2010

(C) The Author(s) 2010. This article is published with open access at Springerlink.com

\begin{abstract}
Purpose The purposes of this study were to compare the health-related quality of life (HRQOL) of long-term social assistance recipients (LTRs) with and without chronic pain and determine the effect of select demographic, social, pain, alcohol, and illicit drug use characteristics on the physical and mental components of their HRQOL.

Methods In this cross-sectional study, which is part of a larger study that evaluated the health and functional abilities of LTRs in Norway, 405 LTRs of which 178 had chronic pain were recruited from 14 of 433 municipalities. Results LTRs with chronic pain were older $(P<.001)$, more often married $(P=.002)$, feeling more lonely, $(P=$ $.048)$, and had more problems with alcohol $(P=.035)$. The final regression model explained $41.2 \%(P<.001)$ of the variance in PCS scores and 32.2\% $(P<.001)$ of the variance in MCS scores. Being in chronic pain $(29.7 \%)$, being older $(4.7 \%)$, and never married (2\%) predicted worse PCS scores.
\end{abstract}

B. Løyland $(\bowtie) \cdot T$. Rustøen

Faculty of Nursing, Oslo University College,

Postbox 4, St. Olavs Plass, 0130 Oslo, Norway

e-mail: Borghild.Loyland@su.hio.no

B. Løyland

Faculty of Medicine, University of Oslo, Oslo, Norway

C. Miaskowski $\cdot$ S. M. Paul

Department of Physiological Nursing, University of California, San Francisco, CA, USA

C. Miaskowski · T. Rustøen

Centre for Shared Decision Making and Nursing Research,

Oslo University Hospital, Oslo, Norway

E. Dahl

Oslo University College, Social Welfare Research Center,

Oslo, Norway
Feeling lonely (11.9\%), having problems with illicit drug use $(5.9 \%)$, and being in chronic pain $(2.9 \%)$ predicted worse MCS scores.

Conclusion LTRs with chronic pain rated both the physical and mental components of HRQOL lower than LTRs without chronic pain. The MCS score in both groups was negatively effected.

Keywords Health-related quality of life - SF-12 . Long-term social assistance recipients - Chronic pain . Physical health · Mental health

$\begin{array}{ll}\text { Abbreviations } \\ \text { HRQOL } & \text { Health-related quality of life } \\ \text { QOL } & \text { Quality of life } \\ \text { LTR } & \text { Long-term social assistance recipient } \\ \text { SF-12 } & \text { Health survey short form } 12 \text { questionnaire } \\ \text { PCS } & \text { Physical component score } \\ \text { MCS } & \text { Mental component score } \\ \text { WES } & \text { Woman's Employment Study }\end{array}$

\section{Introduction}

Norway is a welfare state of a social-democratic type. This implies that public welfare is universal, comprehensive, and generous when compared with other welfare regimes. The major income maintenance system is social insurance. All citizens who fulfill specific criteria are entitled to social insurance benefits. One crucial criterion for most benefits is a work record. Rights to social insurance (e.g., unemployment benefit, sickness pay) are earned by previous labor market participation. People who have not earned the 
right to or exhausted their rights to social insurance and are unable to support themselves, are eligible for social assistance. Unlike social insurance, social assistance provides the last safety net and is a means tested benefit. Usually, social assistance is not as generous as unemployment benefits.

In 2005 , approximately $3 \%$ of the general population in Norway over 17 years of age received social assistance [1]. Forty-two percent of these individuals were long-term social assistance recipients (LTRs) defined as having received social assistance as their main source of income for at least 6 of the last 12 months. These LTRs experience economic strain and have a simpler housing standard than the general population [2]. Of note, in $2005,71 \%$ of LTRs reported serious financial difficulties compared to only $13 \%$ of the general population [3]. In general, LTRs are less educated, have less social resources, lower incomes, and poorer health than the general population [4]. In addition, LTRs and welfare recipients struggle with numerous health issues, (e.g., poorer functional health, depression, anxiety, increased risk of cardiovascular disease, pain), have a higher level of psychological distress, and reduced psychological well-being [5-9]. LTRs are more likely to experience domestic violence, experience feelings of loneliness, and report problems with alcohol and illicit drugs $[4,6]$. The mortality rate of this vulnerable and disadvantaged group is two to three times higher than that of the general population [10].

Chronic pain is a significant and rapidly growing health problem in the general population worldwide [11]. In fact, population-based studies suggest that chronic pain occurs in 11 to $30 \%$ of the general population in the United States and Europe [12-15]. Chronic pain is a medical condition in which biological, psychological, and social factors dynamically interact with each other [11]. In fact, numerous studies have demonstrated that chronic pain leads to negative outcomes for patients, including fear of pain, avoidance of activities that elicit pain, stress-related symptoms, and disability [16-21]. In addition, chronic pain has a negative impact on the health-related quality of life (HRQOL) of individuals in the general population, as well as of individuals with different chronic conditions [22-29]. However, only one study has reported on pain in a sample of social security recipients [8]. In this study, that compared pain locations in social security recipients and non-recipients, social security recipients reported pain more frequently in their hands and legs than non-LTRs.

A variety of definitions of quality of life (QOL) are reported in the literature. In addition, researchers use a number of different paradigms to evaluate HRQOL. For example, many social scientists tend to focus on functional status and overall well-being, and how financial circumstances, social structures, and institutions influence
HRQOL. In contrast, clinical researchers may focus on how biomedical and psychological factors influence the HRQOL of LTRs [30].

Four studies were found that evaluated the self-reported health status of welfare recipients or LTRs [5-8] and three of these studies compared welfare recipients or LTRs with non-recipients $[5,7,8]$. In a study that compared single mothers affected by welfare reform (Woman's Employment Study (WES)) with a national sample of woman, woman over 24 years in the WES sample had significantly lower levels of physical functioning [5]. In another study of 284 LTRs (97\% female), two-fifths of the LTRs rated their health as fair or poor. Compared to the total state welfare population, LTRs were more likely to have mental and physical health problems [6]. Data from the National Population Health survey in Canada found that welfare recipients were more likely to report poor/fair health, poor functional health, and depression compared to non-welfare recipients [7]. In a Swedish study, social security recipients had significantly poorer health measured using the GHQ-12 than non-recipients [8]. Finally, in a study from Canada [9], $56 \%$ of the woman and $45 \%$ of the men on social assistance reported a higher level of distress than other individuals living in the same neighborhood.

An individuals' HRQOL and the relationship between HRQOL and chronic pain can differ with gender [27, 31], age [25], and employment status [24, 32, 33]. For example, in one study [33], younger individuals who were unemployed reported a lower QOL than employed individuals of the same age and older individuals who were employed [33]. In contrast, in a study of young unemployed adults, the majority (67\%) reported their QOL as good [32].In a third study of young unemployed Australians, that used the SF-36 [34], lower health status was reported by those who were unemployed. In one study that examined the relationship between unemployment and QOL [32], the feeling of loneliness was evaluated. No differences in loneliness were found between the unemployed group and the reference group. However, a study of loneliness as a predictor of HRQOL among older caregivers found that loneliness was the most important factor that predicted lower HRQOL among caregivers, as well as older people in general [35]. Loneliness is defined by Peplau and Perlman as an unpleasant experience that arises when a person's network and social relations are deficient [36]. In this study, because a recent report suggested that loneliness was a problem in LTRs, the relationship between loneliness and HRQOL was evaluated.

Several studies have examined the impact of alcohol and substance abuse on HRQOL [37-40]. However, in a recent review, the authors noted that it is difficult to draw valid conclusions about the impact of alcohol and substance abuse on HRQOL. One of the major reasons for these 
inconclusive results is the number of different ways that QOL was defined and measured across studies [37]. In addition, the study samples were rather heterogeneous. However, in a study that used SF-12 to measure HRQOL of adults treated for substance abuse, their HRQOL was lower than that of GP and as low as or lower than patients with other chronic medical conditions [38].

In summary, a limited amount of data suggests that LTRs struggle with a number of chronic health issues, report chronic pain and loneliness, and are more likely to abuse alcohol and illicit drugs. Taken together, all these factors may have a negative impact on HRQOL. However, no studies were found that evaluated the impact of these factors on HRQOL of LTRs with and without chronic pain. Therefore, the purposes of this study were to compare the HRQOL of LTRs with and without chronic pain and determine the effect of select demographic, social, pain, alcohol and illicit drug use characteristics on the physical and mental components of their HRQOL.

\section{Methods}

\section{Design and data collection procedures}

This study is part of a larger study, named: "The study of functional ability among long-term social assistance recipients". The study was funded by the Directorate for Health and Social Affairs in Norway after an evaluation of "The National Activation Trial" from 2000 to 2004. "The National Activation Trial" was done to promote and support new ways to move LTRs away from benefit dependency into work. This evaluation showed that approximately $23 \%$ of the LTRs went back to work [41]. Because the results of the National Activation Trial were relatively modest, to better understand the LTRs' psychosocial characteristics and their functional ability, the current study was funded.

This descriptive, cross-sectional study surveyed people receiving long-term social assistance in Norway about their health and social functioning. Data were collected from January to November 2005. The social welfare authority offices in each of 14 municipalities in Norway were responsible to locate the LTRs who met the study's inclusion criteria. The respondents were sent the survey questionnaires and returned them directly using a postage paid envelope to Oslo University College. LTRs who did not reply received two mailed reminders. Some LTRs who did not respond to the mailed reminders were telephoned; while others were reminded to complete the questionnaires by case workers. These extensive data collection procedures were used because previous experience demonstrated that LTRs are difficult to reach. Some relocate and change their addresses frequently or live at an unknown residence. Others stay temporarily in shelters, hospitals, institutions, or prison. The actual number of LTRs in this study, who were homeless or lived in shelters, is not known because this information was not obtained in the demographic questionnaire.

\section{Sample}

Participants were recruited from 14 of 433 municipalities in Norway. These municipalities were part of "The National Activation Trial". The selected municipalities provided geographic variability including both rural and urban municipalities in different parts of the country. The municipality with the fewest LTRs who satisfied the inclusion criteria had only 10 , while the one with the largest number had 282 recipients. LTRs were included in this study if they had received social assistance as their main source of income for at least 6 of the last 12 months; were between 18 and 60 years of age; and were able to complete the study questionnaires.

As shown in Fig. 1, 1,291 LTRs met the initial inclusion criteria. However, 225 of these individuals were prescreened by case workers as unable to complete the questionnaires because of severe substance abuse problems; insufficient mastery of the Norwegian language; extensive problems with reading and writing; or serious illness. Therefore, 1,066 LTRs were included and 562 responded (i.e., response rate of $52.7 \%$ ). Eleven responders were excluded because they were above 60 years of age. An additional 100 participants were excluded because they were found to be in a work activation program and were no longer on long-term social assistance. Because 12 LTRs did not answer the screening question about having pain and 32 participants could not be clearly placed in either the chronic pain or the no pain group, they were excluded. Consequently, 405 LTRs are included in all of the subsequent comparative analysis. Administrative data ("FD-trygd") were used to compare the 1,291 recipients who met the inclusion criteria with those who responded to the questionnaire. No differences in age, gender, previous receipt of social assistance or social security benefits were found between those LTRs who did and did not return the study questionnaires [42].

\section{Ethical considerations}

When research is done with vulnerable groups, special attention needs to be given to research ethics. This study was planned and performed in a way that protected the LTRs from violations of their right to privacy. All questionnaires that were returned to the research office contained no personal identifying information. Completion of the questionnaires indicated informed consent. The study, including the number of reminders, was approved by the 
Fig. 1 Flow chart of responses to survey questionnaire and categorization of long-term social assistance recipients (LTRs) into pain groups

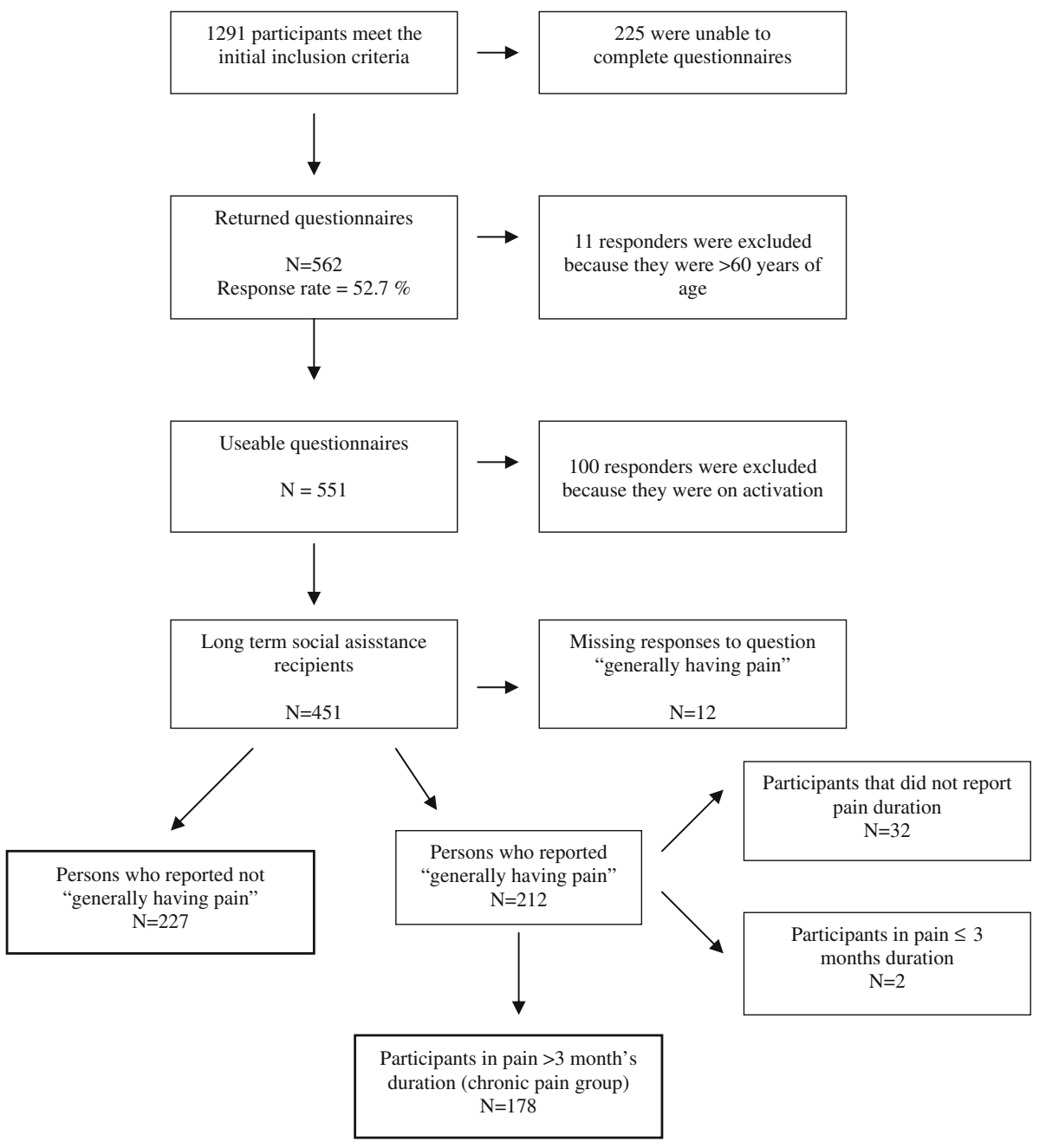

Data Inspectorate and the National Committee for Research Ethics in the Social Sciences and the Humanities.

\section{Instruments and scoring procedures}

The questionnaires that were sent to the LTRs provided information on socio-demographic characteristics, work, health indices, HRQOL, pain, use of alcohol and narcotics, social capital, and childhood difficulties. Only the data on socio-demographic characteristics, pain, feeling lonely, use of alcohol and illicit drugs, and HRQOL are presented in this paper.

The questionnaire was finalized after a pilot test with twelve social assistance recipients in one municipality. Three of the researchers met the social assistance recipients and obtained feedback about the questionnaire.

\section{Socio-demographic characteristics}

Data on age, gender (female $=1$, male $=2$ ), marital status, education $(1=$ primary school, $2=$ secondary school,
$3=$ college/university), living alone (yes $=1$, no $=2$ ), and work (yes $=1$, no $=2$ ) were collected of the LTRs.

Pain

Pain was assessed using a nine-item questionnaire that evaluated for the presence of pain, and if present, its cause, location, duration, intensity, and treatments. In this study, LTRs were categorized into pain groups based on their responses to a screening question about whether or not they were generally in pain.

\section{Categorization of chronic pain}

Chronic pain was defined as pain of $>3$ months duration [12-14]. For the LTR group who answered yes to the question "Do you generally have pain?" the response to the duration question was analyzed. Those LTRs whose pain duration was $>3$ months were classified as chronic pain patients. Those LTRs whose pain duration was $\leq 3$ months were classified as not being in chronic pain $($ yes $=1$, no $=2)$. 


\section{Feeling lonely}

LTRs were asked "Does it happen that you often (1), sometimes (2), seldom (3), or never (4) feel lonely?" This question was used in previous studies of the Norwegian general population by Statistics Norway [43].

\section{Alcohol and illicit drug use questionnaire}

Two items asked about whether the LTRs now or previously had experienced problems with alcohol and illicit drug use (range of responses from "yes some", "yes", collapsed to yes (1) "not now, but earlier", to "no", collapsed to no (2). The items on alcohol and illicit drug use were developed and pilot tested for this study.

\section{$S F-12$}

HRQOL of the LTRs was evaluated using the Norwegian version of the SF-12, which consists of 12 questions about physical and mental health as well as overall health status $[44,45]$. The questionnaire is scored into two components that measure physical (PCS) and mental (MCS) health. SF-12 has been translated into several languages, including Norwegian and thoroughly tested for its psychometric properties [46]. Higher PCS and MCS scores indicate a better HRQOL.

\section{Data analyses}

Data were analyzed using SPSS for Windows (version 17.0). Descriptive analyses were done to assess the characteristics of the sample. Chi-square analyses and independent sample $t$-tests were used to evaluate for differences in demographic, social, and substance abuse characteristics and HRQOL between LTRs with and without chronic pain. Correlation analyses (i.e., Fishers exact test and Pearson's) were used to assess the bivariate relationships between selected variables. Multiple linear regression analyses were used to determine the effect of selected variables on SF-12 physical and mental health component scores. A $P$-value of $<0.05$ was considered statistically significant.

\section{Results}

Differences in demographic, health, and social characteristics between LTRs with and without chronic pain

In the sample of LTRs, $44 \%$ were categorized as having chronic pain. As shown in Table 1, LTRs with chronic pain were significantly older $(P<.001)$, more likely to be married $(P=.002)$, more likely to feel lonely $(P=.048)$, and more likely to have problems with alcohol $(P=.035)$ than LTRs without chronic pain.

Differences in HRQOL between LTRs with and without chronic pain

As shown in Fig. 2, significant differences were found in mean PCS and MCS scores between LTRs with and without chronic pain. The mean PCS and MCS scores were significantly lower in the LTRs with chronic pain (i.e., 38.22, $\mathrm{SD} \pm 10.4$ and $36.76 \mathrm{SD} \pm 13.2$ ) compared to the LTRs without chronic pain (i.e., 51.68, $\mathrm{SD} \pm 7.7$ and 42.30, SD \pm 13.1 , respectively, both $P<.001)$.

Effect of select demographic, pain, and social characteristics on PCS scores

Variables that were hypothesized to influence the PCS scores were analyzed using multiple linear regression. As shown in Table 2, the final model explained $41.2 \%$ of the variance in PCS scores. The $F$ statistic is 18.880 ( $d f$ $11,297)$, and the overall model is statistically significant $(P<.001), N=309$. Chronic pain uniquely explained $29.2 \%$ in PCS scores; age uniquely explained $4.7 \%$, and marital status explained $2 \%$ of the variance, such that being in chronic pain, being older, and never married predicted worse PCS scores.

Effect of selected demographic, pain, and social characteristics on MCS scores

As shown in Table 2, the same independent variables were used in the model to explain the variance in MCS scores. The final model explained $32.2 \%$ of the variance in MCS scores. The $F$ statistic is 12.827 ( $d f 11,297$ ), and the overall model is statistically significant $(P<.001), N=309$. Feeling lonely uniquely explained $11.9 \%$, problems with illicit drug use uniquely explain $5.9 \%$, and chronic pain uniquely explained $2.9 \%$ of the variance in MCS scores such that feeling lonely, having problems with illicit drug use, and being in chronic pain predicted worse MCS scores.

\section{Discussion}

This study is the first to examine the impact of chronic pain on the HRQOL of LTRs. Consist with previous studies [23, 28, 29, 47], LTRs with chronic pain rated both the physical and mental components of HRQOL lower than LTRs without chronic pain. These differences in HRQOL represent not only statistically, but clinically significant 
Table 1 Differences in sociodemographic, health, and social characteristics between longterms social assistance recipients (LTRs) without and with chronic pain
Bold values indicate $P$-value $<0.05$

\begin{tabular}{|c|c|c|c|c|}
\hline Characteristics & $\begin{array}{l}\text { Total LTR sample } \\
(N=405)\end{array}$ & $\begin{array}{l}\text { LTR without chronic } \\
\text { pain }(N=227)\end{array}$ & $\begin{array}{l}\text { LTR with chronic } \\
\text { pain }(N=178)\end{array}$ & $P$-value \\
\hline Age (years), mean (SD) & $34.0(10.9)$ & $31.6(10.2)$ & $37.1(10.9)$ & $<.001$ \\
\hline \multicolumn{5}{|l|}{ Gender, $N(\%)$} \\
\hline Male & $239(59)$ & $141(62)$ & $98(55)$ & \multirow[t]{2}{*}{.152} \\
\hline Female & $166(41)$ & $86(38)$ & $80(45)$ & \\
\hline \multicolumn{5}{|l|}{ Marital status, $N(\%)$} \\
\hline Married/cohabitant & $89(22)$ & $41(18)$ & $48(27)$ & \multirow[t]{3}{*}{.002} \\
\hline Never married & $227(56)$ & $145(64)$ & $82(46)$ & \\
\hline Divorced/separated & $88(22)$ & $41(18)$ & $47(27)$ & \\
\hline \multicolumn{5}{|l|}{ Education, $N(\%)$} \\
\hline Primary school & $191(49)$ & $103(47)$ & $88(52)$ & \multirow[t]{3}{*}{.581} \\
\hline Secondary school & $170(44)$ & $99(45)$ & $71(42)$ & \\
\hline College/university & $29(7)$ & $18(8)$ & $11(6)$ & \\
\hline \multicolumn{5}{|c|}{ Working (6 months-ever), $N(\%)$} \\
\hline Yes & $272(68)$ & $150(70)$ & $122(70)$ & \multirow[t]{2}{*}{.648} \\
\hline No & $125(32)$ & $72(30)$ & $53(30)$ & \\
\hline \multicolumn{5}{|l|}{ Living alone, $N(\%)$} \\
\hline Yes & $203(51)$ & $116(52)$ & $87(49)$ & \multirow[t]{2}{*}{.608} \\
\hline No & $196(49)$ & $107(48)$ & $89(51)$ & \\
\hline \multicolumn{5}{|l|}{ Feeling lonely, $N(\%)$} \\
\hline Often & $140(35)$ & $65(29)$ & $75(42)$ & \multirow[t]{4}{*}{.048} \\
\hline Sometimes & $157(39)$ & $94(42)$ & $63(36)$ & \\
\hline Seldom & $79(20)$ & $50(22)$ & $29(16)$ & \\
\hline Never & $24(6)$ & $14(6)$ & $10(6)$ & \\
\hline \multicolumn{5}{|l|}{ Alcohol problems, $N(\%)$} \\
\hline Yes & $64(16)$ & $28(13)$ & $36(20)$ & \multirow[t]{2}{*}{.035} \\
\hline No & $338(84)$ & $196(87)$ & $142(80)$ & \\
\hline \multicolumn{5}{|c|}{ Problem with illicit drug use, $N(\%)$} \\
\hline Yes & $102(25)$ & $54(24)$ & $48(27)$ & \multirow[t]{2}{*}{.105} \\
\hline No & $301(75)$ & $171(76)$ & 130 (73) & \\
\hline
\end{tabular}

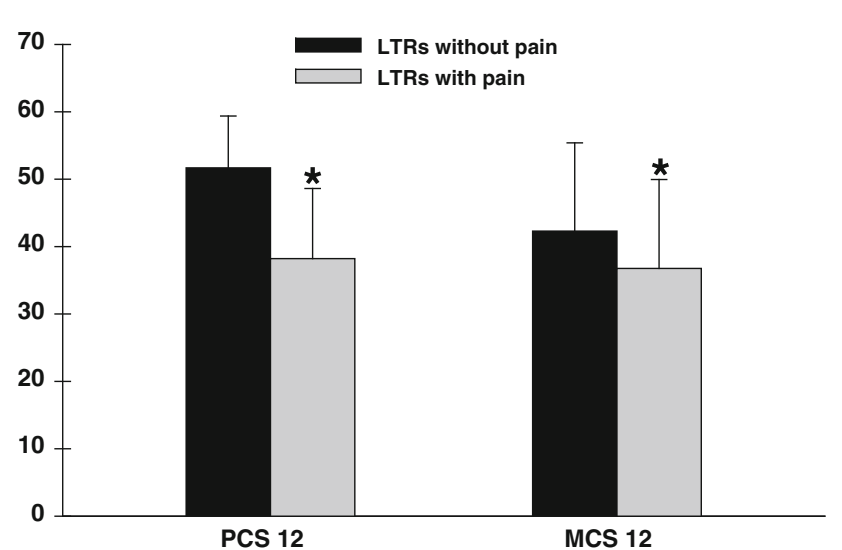

Fig. 2 Differences in SF-12 physical component scores and mental component scores between long-term social assistance recipients with and without chronic pain. All values are plotted as means \pm standard deviations differences in both dimensions of HRQOL (i.e., $d=1.2$, and $d=0.4$ ) [48]. In addition, the fact that LTRs with chronic pain were older and had more problems with alcohol than LTRs without chronic pain is consistent with a recent Canadian study of predictors of chronic non-cancer pain [49].

It is interesting to note that LTRs with chronic pain had a significantly lower PCS score than normative data reported for individuals with chronic low back pain $(\mathrm{PCS}=45.96$, $P<.001$ ) [45]. However, the LTRs without chronic pain had a mean PCS score that was significantly higher than normative data for the general population (PCS 50.3, $P=0.014$, age 18-74) [50]. In fact, LTRs with chronic pain had a lower PCS score than patients with rheumatoid arthritis $(\mathrm{PCS}=39.60, P<.001)$ and cancer $(\mathrm{PCS}=$ 40.76, $P \leq .001$ ) [45]. A potential reason why the physical component of HRQOL of LTRs with chronic pain was 
Table 2 Correlation and multiple linear regression analysis of the relationship between demographic factors, health and social factors, (Pearson's correlation coefficient $(r)$, standardized beta weights (Beta), $R^{2}$-change, $P$-value and $R^{2}$ )

\begin{tabular}{|c|c|c|c|c|c|c|c|c|}
\hline \multirow[t]{2}{*}{ Characteristics } & \multicolumn{4}{|c|}{ Physical health composite score } & \multicolumn{4}{|c|}{ Mental health composite score } \\
\hline & $r$ & Beta & $R^{2}$-change & $P$-value & $r$ & Beta & $R^{2}$-change & $P$-value \\
\hline \multicolumn{9}{|l|}{ Socio-demographic } \\
\hline Age & -.278 & -.271 & .047 & $<.001$ & -.041 & .043 & .001 & .472 \\
\hline Gender & .094 & .044 & .002 & .363 & .003 & .012 & .000 & .811 \\
\hline Education & .045 & -.004 & .000 & .932 & .070 & .016 & .000 & .750 \\
\hline Marital status & & & .020 & .007 & & & .003 & .470 \\
\hline Divorced/sep. vs. married & .016 & .054 & .001 & .408 & .050 & .082 & .003 & .243 \\
\hline Never married vs. married & .057 & -.129 & .008 & .049 & -.046 & -.027 & .004 & .696 \\
\hline Living alone & -.047 & -.023 & .000 & .664 & .061 & -.045 & .001 & .430 \\
\hline Working (ever in past 6 months) & .022 & -.053 & .002 & .271 & .003 & .039 & .001 & .445 \\
\hline \multicolumn{9}{|l|}{ Health } \\
\hline Chronic pain & .594 & .571 & .292 & $<.001$ & .237 & .179 & .029 & $<.001$ \\
\hline \multicolumn{9}{|l|}{ Social } \\
\hline Feeling lonely & -.006 & -.081 & .006 & .091 & .469 & .371 & .119 & $<.001$ \\
\hline Problem with alcohol & .045 & -.024 & .000 & .619 & .159 & .065 & .004 & .208 \\
\hline Problem with illicit drug use & -.039 & -.049 & .002 & .319 & .351 & .265 & .059 & $<.001$ \\
\hline Explained variance $\left(R^{2}\right)$ & & .412 & & & & & .322 & \\
\hline
\end{tabular}

$N=309$

lower than that of an age-matched sample of patients with low back pain is that chronic pain in LTRs is a symptom of a number of chronic medical conditions that impact their HRQOL. Previous studies found that LTRs struggle with numerous health problems [5-9] and have chronic conditions that have a negative impact on their HRQOL [51, 52]. In addition, LTRs are more likely to experience violence, which may result in chronic pain and decrease their physical health [6, 53].

The mean MCS scores for both groups of LTRs were lower than population norms (i.e., 50.6, both $P \leq .001$ ) [50]. However, LTRs with chronic pain had lower MCS scores than LTRs without chronic pain. The fact that LTRs with chronic pain had a lower MCS score is consistent with several studies that found that chronic pain has a negative impact on the HRQOL [23, 25, 27, 47] as well as on the ability of an individual to remain employed.

One potential reason for the low mental score in both groups of LTRs is that these individuals have poorer health, less social resources, lower incomes, lower education [4], and experience more economic strain than the general population [2]. In addition, LTRs were more likely to have mental problems and depression symptoms [5, 7, 8]. Another potential reason for the low MCS scores is that these individuals experience a number of disadvantages over the course of their lives. LTRs experience more childhood difficulties [4, 54] and have a lifestyle with higher rate of accidents or medical conditions associated with a poorer diet and higher rates of smoking and alcohol consumption than the general population [4, 6, 8].

In the present study, chronic pain explained the largest percentage of the variance in PCS scores. This result is not that surprising given the fact that chronic pain has a negative impact on physical function [27, 29, 49] and that physical function decreases with age [31]. Findings from this study suggest that clinicians who care for LTRs should screen these individuals for the presence of chronic pain.

While chronic pain explained the largest percentage of the variance in physical health, loneliness explained the largest percentage of variance in the mental health scores. Only one study was found that evaluated loneliness as a predictor of HRQOL among elderly caregivers [35], and no studies have evaluated the impact of loneliness on the HRQOL of LTRs. Loneliness is not the same as being alone, but people with small social network usually feel more loneliness than people with larger social networks $[55,56]$. In addition, women report more loneliness than men; older people report feelings of loneliness more often than younger individuals, excluding young people between the ages of 19 and 29 who feel more loneliness than adults [43]. One study found that loneliness was the most important factor predicting low HRQOL of older caregivers as well as older people in general [35]. Recent findings suggest that loneliness may lead to depression, sleep 
disturbances, anxiety, and desperation [57]. A recent study found that social loneliness impacted QOL in individuals with serious mental illness who lived in a group home [58]. While loneliness is emerging as a concept that influences HRQOL, additional research is warranted to replicate the findings from this study.

In the present study, illicit drug use was associated with poorer mental health. This finding is consistent with a previous study [38]. However, a recent review noted that it was difficult to draw valid conclusions about the impact of alcohol and substance abuse on HRQOL because of heterogeneous study samples and different ways that QOL was defined and measured [37]. Additional research is warranted on this relationship.

Several limitations of this study need to be acknowledged. First, only a limited amount of information is available on those LTRs who did not return the study questionnaires. When administrative data from 2005 were used to compare the recipients who met the inclusion criteria to those who completed the questionnaire, no significant differences were found in gender, age, work experience, previous receipt of social assistance, and social security benefits [42]. Another limitation is that all of the information was obtained through self-report measures, and some of the questions may be subject to recall bias. It should be noted that one of the questions on SF-12 asked about how pain had impaired on individual's work and daily life which is likely to be related to the PCS score. However, the bivariate correlation between chronic pain and PCS was 0.59. It is not that high, so chronic pain is not all that the PCS score is measuring. Finally, the QOL scores of the LTRs in this study may be higher than the total population of LTRs, because LTRs with serious illness or severe substance abuse problems were excluded from this study.

\section{Conclusion}

Findings from this study suggest that chronic pain in LTRs is associated with poorer physical health. However, both groups of LTRs had lower mental health scores than normative data for the general population. These findings warrant replication in future studies. In addition, longitudinal studies are needed to evaluate the long-term impact of chronic pain on the physical health of LTRs.

Acknowledgments The research is funded by Oslo University College and by the Directorate for Health and Social Affairs Norway.

Open Access This article is distributed under the terms of the Creative Commons Attribution Noncommercial License which permits any noncommercial use, distribution, and reproduction in any medium, provided the original author(s) and source are credited.

\section{References}

1. Sosial-og helsedirektoratet. (2007). Utviklingstrekk $i$ helse- og sosialsektoren. Oslo: Sosial- og helsedirektoratet.

2. SSB. (2008). Økonomi og levekair for ulike grupper (p. 147). Oslo: Statistics of Norway.

3. Myklestad, I., Rognerud, M., \& Johansen, O. R. (2008). Utsatte grupper og psykisk helse. Oslo: Folkehelseinstituttet.

4. van der Wel, K., Dahl, E., Lødemel, I., Løyland, B., Ohrem Naper, S., \& Slagsvold, M. (2006). Funksjonsevne hos langtidsmottakere av sosialhjelp. Oslo: Høgskolen i Oslo.

5. Kaplan, G. A., Siefert, K., Ranjit, N., Raghunathan, T. E., Young, E. A., Tran, D., et al. (2005). The health of poor women under welfare reform. American Journal of Public Health, 95(7), 1252-1258.

6. Taylor, M., \& Barusch, A. (2004). Personal, family, and multiple barriers of long-term welfare recipients. Social Work, 49(2), 175-183.

7. Vozoris, N. T., \& Tarasuk, V. S. (2004). The health of Canadians on welfare. Canadian Journal of Public Health, 95(2), 115-120.

8. Baigi, A., Lindgren, E. C., Starrin, B., \& Bergh, H. (2008). In the shadow of the welfare society ill-health and symptoms, psychological exposure and lifestyle habits among social security recipients: a national survey study. BioPsychoSocial Medicine, 2, 15.

9. Caron, J., Latimer, E., \& Tousignant, M. (2007). Predictors of psychological distress in low-income populations of Montreal. Canadian Journal of Public Health, 98(S1), 35-44.

10. Naper, S. O. (2009). All-cause and cause-specific mortality of social assistance recipients in Norway: A register-based follow-up study. Scandinavian Journal of Public Health, 37(8), 820-825.

11. Gatchel, R. J., Peng, Y. B., Peters, M. L., Fuchs, P. N., \& Turk, D. C. (2007). The biopsychosocial approach to chronic pain: Scientific advances and future directions. Psychological Bulletin, 133(4), 581-624.

12. Catala, E., Reig, E., Artes, M., Aliaga, L., Lopez, J., \& Segu, J. (2002). Prevalence of pain in the Spanish population: Telephone survey in 5000 homes. European Journal of Pain, 6(2), 133-140.

13. Blyth, F. M., March, L. M., Brnabic, A. J. M., Jorm, L. R., Williamson, M., \& Cousins, M. J. (2001). Chronic pain in Australia: A prevalence study. Pain, 89(2-3), 127-134.

14. Rustøen, T., Wahl, A. K., Hanestad, B. R., Lerdal, A., Paul, S., \& Miaskowski, C. (2004). Prevalence and characteristics of chronic pain in the general Norwegian population. European Journal of Pain, 8(6), 555-565.

15. Breivik, H., Collett, B., Ventafridda, V., Cohen, R., \& Gallacher, D. (2006). Survey of chronic pain in Europe: Prevalence, impact on daily life, and treatment. European Journal of Pain, 10(4), 287-333.

16. Turner, J. A., Jensen, M. P., \& Romano, J. M. (2000). Do beliefs, coping, and catastrophizing independently predict functioning in patients with chronic pain? Pain, 85(1-2), 115-125.

17. Jensen, M. P., Turner, J. A., \& Romano, J. M. (2001). Changes in beliefs, catastrophizing, and coping are associated with improvement in multidisciplinary pain treatment. Journal of Consulting and Clinical Psychology, 69(4), 655-662.

18. McCracken, L. M., Carson, J. W., Eccleston, C., \& Keefe, F. J. (2004). Acceptance and change in the context of chronic pain. Pain, 109(1-2), 4-7.

19. Turk, D. C., Robinson, J. P., \& Burwinkle, T. (2004). Prevalence of fear of pain and activity in patients with fibromyalgia syndrome. Journal of Pain, 5(9), 483-490.

20. Boersma, K., \& Linton, S. J. (2006). Psychological processes underlying the development of a chronic pain problem: a prospective study of the relationship between profiles of psychological variables in the fear-avoidance model and disability. Clinical Journal of Pain, 22(2), 160-166.

21. Dersh, J., Gatchel, R. J., Mayer, T., Polatin, P., \& Temple, O. R. (2006). Prevalence of psychiatric disorders in patients with 
chronic disabling occupational spinal disorders. Spine, 31(10), $1156-1162$.

22. Hoffman, B. M., Papas, R. K., Chatkoff, D. K., \& Kerns, R. D. (2007). Meta-analysis of psychological interventions for chronic low back pain. Health Psychology, 26(1), 1-9.

23. Antonopoulou, M., Alegakis, A., Hadjipavlou, A., \& Lionis, C. (2009). Studying the association between musculoskeletal disorders, quality of life and mental health. A primary care pilot study in rural Crete, Greece. BMC Musculoskeletal Disorders, 10(143), 1-8.

24. Wahl, A., Rustøen, T., Rokne, B., Lerdal, A., Knudsen, Ø., Miaskowski, C., et al. (2009). The complexity of the relationship between chronic pain and quality of life: A study of the general Norwegian population. Quality of Life Research, 18(8), 971-980.

25. Rustøen, T., Wahl, A. K., Hanestad, B. R., Lerdal, A., Paul, S., \& Miaskowski, C. (2005). Age and the experience of chronic pain: Differences in health and quality of life among younger, middleaged, and older adults. Clinical Journal of Pain, 21(6), 513-523.

26. Becker, N., Bondegaard Thomsen, A., Olsen, A. K., Sjøgren, P., Bech, P., \& Eriksen, J. (1997). Pain epidemiology and health related quality of life in chronic non-malignant pain patients referred to a Danish multidisciplinary pain center. Pain, 73(3), 393-400.

27. Bingefors, K., \& Isacson, D. (2004). Epidemiology, co-morbidity, and impact on health-related quality of life of self-reported headache and musculoskeletal pain-a gender perspective. European Journal of Pain, 8(5), 435-450.

28. Lee, S., Chen, P. P., Lee, A., Ma, M., Wong, C. M., \& Gin, T. (2005). A prospective evaluation of health-related quality of life in Hong Kong Chinese patients with chronic non-cancer pain. Hong Kong Medical Journal, 11(3), 174-180.

29. Jensen, M. K., Thomsen, A. B., \& Højsted, J. (2006). 10-year follow-up of chronic non-malignant pain patients: Opioid use, health related quality of life and health care utilization. European Journal of Pain, 10(5), 423-433.

30. Wilson, I. B., \& Cleary, P. D. (1995). Linking clinical variables with health-related quality of life. A conceptual model of patient outcomes. Journal of the American Medical Association, 273(1), 59-65.

31. Rustøen, T., Wahl, A. K., Hanestad, B. R., Lerdal, A., Paul, S., \& Miaskowski, C. (2004). Gender differences in chronic painfindings from a population-based study of Norwegian adults. Pain Management Nursing, 5(3), 105-117.

32. Axelsson, L., Andersson, I., Eden, L., \& Ejlertsson, G. (2007). Inequalities of quality of life in unemployed young adults: A population-based questionnaire study. International Journal for Equity in Health, 6(1), 1-9.

33. Hultman, B., \& Hemlin, S. (2008). Self-rated quality of life among the young unemployed and the young in work in northern Sweden. Work, 30(4), 461-472.

34. Scanlan, J. N., \& Bundy, A. C. (2009). Is the health of young unemployed Australians worse in times of low unemployment? Australian and New Zeland Journal of Public Health, 33(1), 79-82.

35. Ekwall, A. K., Sivberg, B., \& Hallberg, I. R. (2005). Loneliness as a predictor of quality of life among older caregivers. Journal of Advanced Nursing, 49(1), 23-32.

36. Peplau, L., \& Perlman, D. (1982). Perspectives on loneliness. In L. P. Peplau \& D. Perlman (Eds.), Loneliness: A Sourcebook of Current Theory, Research and Therapy. New York: John Wiley and Sons.

37. Zubaran, C., \& Foresti, K. (2009). Quality of life and substance use: Concepts and recent tendencies. Current Opinion in Psychiatry, 22(3), 281-286

38. Smith, K. W., \& Larson, M. J. (2003). Quality of life assessments by adult substance abusers receiving publicly funded treatment in Massachusetts. American Journal of Drug and Alcohol Abuse, 29(2), 323-335.
39. Urbanoski, K., Cairney, J., Adlaf, E., \& Rush, B. (2007). Substance abuse and quality of life among severely mentally ill consumers. Social Psychiatry and Psychiatric Epidemiology, 42(10), 810-818.

40. Astals, M., Domingo-Salvany, A., Buenaventura, C. C., Tato, J., Vazquez, J. M., Martin-Santos, R., et al. (2008). Impact of substance dependence and dual diagnosis on the quality of life of heroin users seeking treatment. Substance Use and Misuse, 43(5), 612-632.

41. Johannessen, A., \& Lødemel, I. (2005). Tiltaksfors $\phi k e t:$ mot en inkluderende arbeidslinje? Oslo: Høgskolen i Oslo.

42. Dahl, E., \& van der Wel, K. (2009). A forske på marginaliserte grupper. Fontene forskning, 2(1), 154-164.

43. Thorsen, K., \& Clausen, S. (2009). Hvem er de ensomme? Oslo: Statistics of Norway.

44. Ware, J. E., Kosinski, M., Bayliss, M. S., McHorney, C. A., Rogers, W. H., \& Raczek, A. (1995). Comparison of methods for the scoring and statistical analysis of SF-36 health profile and summary measures: Summary of results from the Medical Outcomes Study. Medical Care, 33(4suppl), 264-279.

45. Ware, J. E., Kosinski, M., Turner-Bowker, D. M., \& Gandek, B. (2005) (eds). How to Score Version 2 of the SF-12® Health Survey. Lincoln: Quality Metric Incorporated.

46. Loge, J. H., \& Kaasa, S. (1998). Short form 36 (SF-36) health survey: Normative data from the general Norwegian population. Scandinavian Journal of Social Medicine, 26(4), 250-258.

47. Sjøgren, P., Ekholm, O., Peuckmann, V., \& Grønbæk, M. (2009). Epidemiology of chronic pain in Denmark: An update. European Journal of Pain, 13(3), 287-292.

48. Cohen, J. (1994). The Earth is round $(\mathrm{p}<.05)$. American Psychologist, 49(12), 997-1003.

49. Rashiq, S., \& Dick, B. D. (2009). Factors associated with chronic noncancer pain in the Canadian population. Pain Research and Management, 14(6), 454-460.

50. Gandek, B., Ware, J. E., Aaronson, N. K., Apolone, G., Bjorner, J. B., Brazier, J. E., et al. (1998). Cross-validation of item selection and scoring for the SF-12 health survey in nine countries: Results from the IQOLA Project. Journal of Clinical Epidemiology, 51(11), 1171-1178.

51. Wang, H.-M., Beyer, M., Gensichen, J., \& Gerlach, F. (2008). Health-related quality of life among general practice patients with differing chronic diseases in Germany: Cross sectional survey. BMC Public Health, 8(246), 1-12.

52. Saarni, S., Härkänen, T., Sintonen, H., Suvisaari, J., Koskinen, S., Aromaa, A., et al. (2006). The impact of 29 chronic conditions on health-related quality of life: A general population survey in finland using 15D and EQ-5D. Quality of Life Research, 15(8), 1403-1414.

53. Pape, H., \& Stefansen, K. (2004). Den skjulte volden? En unders $\phi$ kelse om Oslobefolkningens utsatthet for trusler, vold og seksuelle overgrep. Oslo: Nasjonalt kunnskapssenter om vold og traumatisk stress.

54. Lorentzen, T., \& Nielsen, R. (2008). Gair fattigdom $i$ arv? Langtidseffekter av a vokse opp i familier som mottar sosialhjelp. Oslo: Fafo.

55. Halvorsen, K. (2005). Ensomhet og sosial isolasjon $i$ vair tid. Oslo: Gyldendal Norsk Forlag.

56. Meeuwesen, L., Hortulanus, R., \& Machielse, A. (2001). Social contacts and social isolation: A typology. Netherlands Journal of Social Sciences, 37(2), 132-154.

57. Lunaigh, C. O., \& Lawlor, B. A. (2008). Loneliness and health of older people. International Journal of Geriatric Psychiatry, 23(12), 1213-1221.

58. Weiner, A., Roe, D., Mashiach-Eizenberg, M., Baloush-Kleinman, V., Maoz, H., \& Yanos, P. (2009). Housing model for persons with serious mental illness moderates the relation between loneliness and quality of life. Community Mental Health Journal. (Epub). 